\title{
Competitive Gains in Clusters State of Goiás
}

\author{
Ernane Rosa Martins ${ }^{1}$, Solange da Silva ${ }^{2}$ \\ ${ }^{1}$ Coordination of Information Technology Area, Federal Institute of Education Science and Technology Goias, Luziânia, Brazil \\ ${ }^{2}$ Department of Industrial and Systems Engineering, University of Goiás, Goiânia, Brazil
}

\section{Email address:}

ernane.martins@ifg.edu.br (E. R. Martins), solansilva.ucg@gmail.com (S. da Silva)

\section{To cite this article:}

Ernane Rosa Martins, Solange da Silva. Competitive Gains in Clusters State of Goiás. Science Journal of Business and Management. Vol. 3, No. 6, 2015, pp. 276-284. doi: 10.11648/j.sjbm.20150306.19

\begin{abstract}
This research aims to study the competitive gains of some Local Productive Arrangements (LPA) selected, in the State of Goiás. This study aims to broaden the understanding of earnings and benefits provided by them. This research is characterized as qualitative and exploratory nature, and the method adopted for its implementation is the study of multiple cases. Three clusters were analyzed in the State of Goiás As a result, between competitive gains identified in the studied clusters stand out: Specialization of mass production and training of skilled workers identified in all clusters. The survey results revealed some relevant points about the competitive gains provided by the studied clusters, among which can be highlighted.
\end{abstract}

Keywords: Local Clusters, Competitive Gains, Corporate Earnings

\section{Introduction}

According Casarotto and Pires (2001), unless the SMEs have a good local market niche, is unlikely to have global reach to continue acting individually, which leads to a new organizational model, networking [1].

Venturi and Philip (2007) point out that the world economy has imposed the agents responsible for development policy formulation the search for new concepts and new ways of thinking about productive organization in the search for new forms of negotiation and alliances, which experiences arise and innovation [2].

According to Castro (2009), the clusters can be defined as a geographical concentration of enterprises in a particular sector, in order to seek competitive advantages locational [3].

Thus, the research question of this paper is: What are the competitive gains are provided by LPAs studied?

The purpose of this article is to study the competitive gains of selected clusters, located in the state of Goias.

The proposed methodology for the development of the research was defined as a multiple case study, with exploratory, involving literature and documentary qualitative.

This work is justified by the contribution which could bring in theory, with definition, constitution and comparison of LPAs, establishing cooperation and strengthening of the participating companies.

It is hoped with this study contribute to the academic research in three clusters with a significant economic role in the State of Goiás, experiencing the difficulties encountered in practice in companies that are part of these. Also contribute to the clusters themselves, increasing the understanding of earnings and benefits thereof.

Due to the lack of studies that take into account this issue and the empirical evidence found, this work can improve understanding of the gains of these types of cooperatives in the state of Goias.

So based on the above, this article is divided into five sections, in this present section presents besides the introduction, the definition of the research problem, the goal, the rationale and importance of the study and structure of this research. Section 2 presents the theoretical framework, with the formation of a conceptual and theoretical base, providing subsidies for the development of this study. Section 3 presents the method used and the technical and methodological procedures used for the study. Section 4 presents the analysis and discussion of the results obtained in the research, performing the analysis of the studied clusters, in order to verify the homogeneity and heterogeneity between the perceptions obtained from respondents. Finally, in section 5 shows the relationships identified between the constructs used and the cases studied in the research. 


\section{Literature Review}

\subsection{Local Clusters}

As Issa et al. (2015), the concept of LPA is not fully defined, since for each author, a research center or institution, it has a variety of factors to determine it [4].

Brito and Albagli (2003, p.3) defines clusters as territorial agglomerations of economic, political and social agents focusing on a specific set of economic activities that have the same ties that incipient. Usually involve the participation and interaction of companies that can range from producers of final goods and services to suppliers of inputs and equipment, consulting and service providers, traders, customers and others and its many forms of representation and association. Also include various other public and private institutions concerned with: training of human resources, such as technical schools and universities; research, development and engineering; policy, promotion and funding [5].

Can be highlighted some common characteristics for these agglomerations, including: integrating a set of companies with production expertise; mainly consist of small and medium enterprises; have several support institutions (economic agents, social, political); They feature interactive links between agents; seek collective efficiency gains generated by the agglomerative process and promote cooperative practices [6].

The clusters can be characterized as institutions capable of triggering regional integration processes based on a harmonization effort between dynamics of cooperation and competition. Keeping the focus on a specific sector of the developmental dynamics, clusters differ from clusters clump together because the micro and small businesses and stimulate the internal growth of integrated development practices [7].

Porter (1998) points out that clusters is the union firms in a sector in the same territorial area, which aggregate over the entire value chain [8].

The definition of Caporall and Volker (2004), LPAs are a particular type of cluster, made up of small and medium enterprises, grouped around a profession or a business, in which emphasize the role of formal and informal relationships between companies and other institutions involved. The companies share a common culture and interact as a group, with the local socio-cultural environment. These interactions, cooperative and / or competitive nature, extend beyond the business relationship and tend to generate, apart from the economies of scale, external economies associated with the socialization of knowledge and the reduction of transaction costs. Note that, in these systems, the production units may have similar and / or complementary activities in which predominates the division of labor among its different participants [9].

It is understood by LPA territorial agglomerations of economic agents, political and social focus on a specific set of economic activities that have links, even if incipient. Thus, the study of a cluster should include internal and external actors to productive activity in order to allow for understanding economic, social and industry policy studied [10].

The SME clustering phenomenon is called in the literature as clusters (Porter, 1998). In Brazil, the most common term is the LPA, published by the National Development Bank (BNDES) and adopted by different public and private agencies $[11,12]$.

The clusters refer to groupings of a set of companies concentrated geographically and by sector, with related capabilities or the like, of all sizes, but usually with a significant number of small and medium enterprises not vertically integrated. These companies, in turn, attract suppliers and other related and supporting industries, whose presence and importance in the local systems are determined solely by market forces. [13]

The Ministry of Development, Industry and Foreign Trade (MDIC) coined the term clusters to designate regional clusters of companies in the same industry. The term was prepared by the Permanent Working Group for Local Production Arrangements (GTP-LPA) and refers to regions that have a significant number of enterprises and individuals working in a predominantly productive activity and to share cooperation and governance mechanisms [14].

Thus, according to the authors Marini e Silva (2010); Silva, Santos and Candide (2011); Ribeiro Nascimento, Junior and Morato (2013); Teixeira and Teixeira (2010); Vidigal and Fields (2011); Saraceni, Junior and Resende (2013); Sordi and Meireles (2011); Vieira, Galdamez, Souza Oliveira (2013); Masquietto, Grandson, Giuliani (2010), LPAs are territorial settlements or geographical concentration of economic, political and social agents focusing on a specific set of economic activities that have production linkages, interaction, cooperation and learning. They also include several other public and private organizations $[15,16,17,18$, 19, 20, 21, 22, 23].

According to Castro and Esteban (2010) this approach is a systematic way of looking at reality. Any productive activity must be seen as inseparable from territorially located dynamical systems. It must seek to understand them from the nature of the interactions between its various economic actors, social and political, valuing the flows of knowledge and learning processes. It is a very broad approach, both from an analytical point of view, as policy, from simple production structures more complex, regardless of the size of companies and the predominant activities sector [24].

According to Ribeiro, Nascimento, Junior and Morato (2013); Calheiros (2010); Silveira, Pereira, Dugo and Ruiz (2011); Martin (2013); Teixeira and Teixeira (2010); Nadae, Galdamez, Carpinetti, Souza Oliveira (2014), Cluster is a geographically concentrated cluster of organizations with similar characteristics, with great capacity for cooperation, with an emphasis on competition. Are productive organizations whose characteristics have historical character as a result of the economic environment, culture and local social relations [17, 25, 26, 27, 18, 28, 29].

From Macedo settings (2011); Teixeira and Teixeira (2010); Kings and Neto (2012); Olivares and Dalcol (2014); SPILs can be defined as clusters that have interdependence, 
articulation and expressive links of production and that these result in interaction, cooperation and learning, with potential to increase the innovative capacity, competitiveness and local development [30,18, 31, 32].

\subsection{Competitive Gains Provided by Local Clusters}

The idea that there is advantage in clusters and clusters is old. According to Schmitz and Nadvi (1999), the theory begins with the classic "Principles of Economics" by Alfred Marshall (first edition 1890). Marshall (1982, p. 231), addresses a pioneer in the theme of "concentration of specialized industries in certain locations," showing that the clustering of industries could help businesses, especially small ones, to take advantage. Marshall states that "clustered industries" involved in similar activities generated a set of economic benefits (called "Marshallian external economies"). Those born advantages in the division of labor between the producers of the same industrial sector concentrated in one geographical region [33, 34, 35].

As Markusen (1995), arising from LPA earnings are defined as being the appropriation of the benefits and advantages derived from LPAs. These are in a stable cluster and can share a single cultural identity and a shared industrial capacity [36].

Marshal (1982) has noted that the approaches brought many benefits through economies of scale, and this economy depends not only on the size of the company individually, but the overall shape production. This statement also corresponds to the contemporary thinking and Nadvi Schmitz (1999), which states that the process of cluster formation facilitates efficiency gains [34, 33].

According to Wegner and Misocsky (2010) interorganizational relationships, lead to the possibility of relational returns, which can not be generated by any of the organizations individually and can only be created through the contributions of partners in an alliance. The essence of the cooperative relationship is therefore a real possibility that the union of partners and distinctive resources they bring to the relationship to be able to generate a synergy that, in isolation, could not be obtained [37].

As Rao and Serpa (2009), companies of LPAs, have, in their origin, the following expectations: to seek new markets, reduce costs, sell in groups, create and develop new products and more efficient production processes, increase the productive capacity of now, engage in innovation projects, improving the company's image, plan joint purchases and create differential against the competition [38].

The main alternative way to solving problems faced by exporting SMEs on international competitiveness is the formation of groups that enhance the productive capacity and reduce promotion and production costs. The idea of working in associative bases enables companies to hit the market in a sustainable, competitive and sustainable manner.

According to Silva and Hewings (2010), the clustering of companies whose production processes are similar or complementary, brings benefits to its members, not only for the possibility of increasing the bargaining power of the group of companies in the negotiations with suppliers and customers, but also because it allows the interaction between the agents involved in the production process, which in turn generates a spillover of knowledge to all lumped firms [39].

Marion Sonaglio and Son (2010) confirms that the joint action of a group of companies in the same industry brings benefits to local economic development and sustainability of companies. It is further understood that in today's rapid technological change scenario, competitiveness is no longer based solely on price, but mainly in the construction of specific skills for the acquisition of knowledge and innovation as the efficiency gains depend on the innovative trajectory [40].

According Gohr et al., (2014), the LPA builds various types of knowledge that can be shared between companies of the arrangement, this happens because of interpersonal relationships and links between organizations, due to trust that exists between companies facilitating the flow of information, mutual assistance, and the creation of new resources for businesses. [41]

As Mazzaro et al, (2009), there are certain characteristics present in clusters that positively influence the productivity and most importantly, productivity growth: access to inputs, specialized personnel and information, complementarities between the activities of the various participants, access to institutions and public goods and incentives for performance measurement (benchmarking) [42].

The predominance of SMEs in LPA feeds the expectation that links between companies are strengthened and that local institutions support strengthen cooperative actions, conducted among both productive agents as suppliers and distribution structure [43].

Local ties bring benefits to the geographical proximity of managers and workers can meet in person to discuss the problems and propose solutions. Workers who operate in similar environments are likely to find context-specific problems and are able to develop the skills necessary to solve them [44].

The connection and interaction between individuals, with equal and different skills complement their experiences, presenting a collective process and distributed knowledge creation and innovation [45].

A widely known approach, and perhaps the most used for analysis of productive clusters, is the "Porter Diamond", described in the book of Michael Porter titled "The Competitive Advantage of Nations" published in 1989, as empirical studies in several countries, focusing mainly on clusters, their strategies and competitiveness. The four sides of the diamond are: conditions of factors (resources, skills, technologies, capital, etc.), demand conditions, links to relate and assist industries and firms' strategy, structure and competition. Each of the economic activities is seen as part of a cluster of activities and agents [46].

As the world is increasingly moving towards an economy based on knowledge and information levels are advancing, the clusters provide not only collective economic benefits, increasing the overall competitiveness of enterprises, but also 
individual benefits through technological innovation within the various organizations of the network [47].

Sampaio (2009) states that the fact that the Micro, Small and Medium Enterprises (MSMEs) belong to clusters brings the following benefits: increased access to information; the ability to influence decisions outside the controlled environment spheres by companies; improving image; the optimization of resources and the possibility of cost savings [48].

As Brandão (2013), the LPAs earn substantial sums to the social, economic, territorial, cultural and environmental, as depending on its production process, can generate positive impacts and / or negative local and even influence in similar proportions others territories. LPAs contribute to reducing market uncertainties and the sharing of information $[49,50]$.

According to Castro (2010), the main competitive advantages resulting from agglomeration economies in clusters, as regards marketing and marketing are: gains of scale through joint sales through business exchanges, trading platforms and others; and exploitation of territorial identity as an intangible wealth which adds itself to products of value (through the creation of Collective Brands, Origin Stamps and Geographical Indications) [51].

The approach that will be addressed in this research is to reference the work of Cezarino and Campomar (2006), which summarizes 14 participating companies competitive advantages of clusters and clusters: information flow on the segment; Specialized support infrastructure; Specialized suppliers; Suppliers of substitute goods; Reinvestment of income in the activity; Burden sharing and R \& D risks; Exchange of experiences on new opportunities; product lines with superior quality; Pressure on the market; Sharing of resources; Strengthening purchasing power; Force to operate in international markets; Specialization of production; Mass training of skilled workers [52].

This study was based on several advantages presented from the point of view of different authors such as:

Porter (1989): Flow intense information, presence of support institutions, infrastructure and skills training [53]. Porter (1998): increase of knowledge about the market, improvement in the quality and speed of product development and the consequent significant increase in revenues [8].

Scitovsky (1954): complementary goods providers to activity expanding product; producers of substitutes production factors to those used by the activity expanding and producers of goods consumed by individuals whose income is increased by the expansion of activity [54].

Amato Neto (2000): combining skills and use know-how of other companies; share the burden of carrying out technological research, development and sharing the acquired knowledge; share risks and explore new opportunities costs, experimenting together and offer the easy possibility of subcontracting and outsourcing of the production process; exert greater pressure on the market, increasing the competitive strength in customer benefit; share resources, with special emphasis on being underutilized; strengthen the purchasing power and more strength to work in international markets [55].

Tristan (2000): increased productivity, raw material, labor, labor, machinery, information, products and more qualitative services and even innovative [56].

Humphrey and Schmitz (1998): stipulation specialty of each producer; emergence of suppliers of raw materials and machinery; emergence of agents who sell to distant and international markets; emergence of specialist companies in technological, financial and accounting services; emergence of a class of employees with specific qualifications and skills; emergence of associations to conduct lobbying specific tasks for all of its members [57].

\section{Research Methodology}

The research is characterized as qualitative, that was adequate for the intended study, for the purpose of the study is to examine complex and particular situations to obtain relevant data. In surveys of this nature we seek to understand social and human activities in the subjective aspects prevail over the objective aspects [58].

According to Godoy (1995), qualitative research occupies a recognized place between various existing technical possibilities when you want to study the phenomena involving human beings and their social relations [59].

This study is also characterized as exploratory for having the purpose to deepen the theme of business arrangements and get to the problem of response more precisely. Exploratory research is indicated when more accurately define the problem it is necessary, analyzing the alternatives, developing the questions or hypotheses and isolate and classify the variables as dependent or independent [60].

The most appropriate method for this research is the study of multiple cases or multicase, to study some clusters, in the State of Goiás. According to Gil (2002) a multicase is defined as a rational and systematic procedure in which their scope is to provide answers the proposed issues in order to contribute to the specific knowledge [61].

The case study was chosen because it is a study of empirical investigating a particular phenomenon, usually contemporary, within a real life context, when the boundaries between phenomenon and context in which it operates are not clearly defined. In the case of an in-depth analysis of one or more objects (cases), allowing its broad and detailed knowledge [61]. Its aim is to deepen the knowledge about a problem not sufficiently defined, to stimulate the understanding, suggest hypotheses and questions or simply develop the theory [62]. They try to explain why a decision or set of decisions were taken, how they were implemented and what results have been achieved [63].

According to Miguel et al. (2012), this technique allows to know a phenomenon, in depth, providing support new theories and increase understanding of real and contemporary events [64].

The survey was conducted in three clusters located in the interior of Goiás: one in Mara Rosa, one in the North Star and the other in São Luís de Montes Belos. 
Eisenhardt (1989), says that the use of multiple data sources and iteration to the literature enables the achievement of greater construct validity of the research. The crossing of the resulting information from different sources allows greater consistency in the analysis of individual cases and cross-analysis of the data [65].

To preserve the identity of LPAs they received the name of LPA1, LPA2, LPA3. The segments of the clusters are presented in Table 1.

Table 1. Selected companies for research.

\begin{tabular}{lll}
\hline Case study & Code & Segment \\
\hline 1 & LPA1 & Saffron \\
2 & LPA2 & Ceramics \\
3 & LPA3 & Dairy \\
\hline
\end{tabular}

The clusters were chosen because they present more consistent answers and more continuous policies [51].

Respondents of the clusters were selected on-site visit, being chosen associates who were active within the LPA searched.

The most appropriate sources of evidence were used for case studies from the perspective of Yin (2005): literature review, document analysis and field research [63].

Through literature were identified and analyzed studies related to LPAs issues in order to support the study and allow discussion of the findings and their comparison with the literature.

In order to obtain more information on the selected clusters, the documents were analyzed: Development Plan of LPAs (2006-2007), developed with the Goiás government support, Sectec, RG-LPA, the National Development Bank (BNDES), Report RedeSist and the MDIC.

According to Marconi and Lakatos (2011), field research is a strategy used in order to get information and / or knowledge about a problem, for which demand a response, which wants to prove [66].

The field research in the clusters was conducted through interviews by appointment, made in 2014, through on-site visit, which were recorded with the permission of the members, except for LPA Dairy in which it was only allowed to interview as part contained in the questionnaire without recording.

In this qualitative research, the interviews provided information that made it possible to identify the competitive gains of the studied clusters. It was used content analysis to analyze strategy of research data.

According Triviños (1987), content analysis is considered a "set of techniques" involving the classification of concepts, coding and categorization of them [67].

According to Godoy (1995) content analysis has three stages: pre-analysis, material exploration and treatment of results [59].

In pre-analysis, the collected material is organized, and establish a work schedule that should be precise, well-defined yet flexible procedures. The exploration phase of the material involves procedures such as encryption, classification and categorization of the collected material. The results of the treatment phase involves reflection and intuition with empirical emplacements, establishing relationships and deepening the connections between the ideas identified [67].

In this study, the pre-analysis phase consisted of organizing the material collected during the search in clusters, and a dynamic reading of it. In the material exploration phase was prepared tables of each individual network to facilitate the exploitation and analysis, in depth, the collected data. Finally, the treatment phase of the results consisted of a qualitative analysis, which verified the homogeneity and heterogeneity between the perceptions of members and managers of the analyzed clusters.

The method of conjoint analysis was adopted to enable the measurement of the competitive gains of the companies involved in different segments and also allow the ranking of each of these gains in order of importance.

\section{Analysis and Discussion of the Results}

In this section we present a joint analysis of the studied clusters, in order to verify the homogeneity and heterogeneity between the perceptions obtained from respondents. This analysis allows to deepen the understanding of the competitive gains realized on LPAs.

The analysis sought to verify the confirmation or not of the research proposition and provides subsidies to propose inferences based on empirical data and theoretical references.

It sought to analyze the clusters according to the work of Cezarino and Campomar (2006).

In Table 2, a summary of the vested benefits is presented, identified in the associated clusters, according to the work of Cezarino and Campomar (2006).

Table 2. Analysis of the benefits of local production arrangements, according Cezarino and Campomar.

\begin{tabular}{|c|c|c|c|}
\hline Benefits & LPA1 & LPA2 & LPA3 \\
\hline Flow of information on the segment & $\mathrm{X}$ & & \\
\hline \multicolumn{4}{|l|}{ Specialized support infrastructure } \\
\hline \multicolumn{4}{|l|}{ Specialized suppliers } \\
\hline \multicolumn{4}{|l|}{ Substitute goods suppliers } \\
\hline Investment income in the activity & & $\mathrm{X}$ & $\mathrm{X}$ \\
\hline Burden sharing and $\mathrm{R} \& \mathrm{D}$ risks & & $\mathrm{X}$ & $\mathrm{X}$ \\
\hline \multicolumn{4}{|c|}{ Exchange of experiences on new opportunities } \\
\hline Product lines with superior quality & & $\mathrm{X}$ & $\mathrm{X}$ \\
\hline \multicolumn{4}{|l|}{ Pressure on the market } \\
\hline \multicolumn{4}{|l|}{ Resource Sharing } \\
\hline \multicolumn{4}{|l|}{ Strengthening the purchasing power } \\
\hline \multicolumn{4}{|l|}{ Force to operate in international markets } \\
\hline Production specialization & $\mathrm{X}$ & $\mathrm{X}$ & $\mathrm{X}$ \\
\hline Mass training of skilled workers & $\mathrm{X}$ & $\mathrm{X}$ & $\mathrm{X}$ \\
\hline
\end{tabular}

As shown in Table 2 can be seen that among the vested benefits:

Flow segment information is identified in one of three, $33.3 \%$;

Specialized support infrastructure has not been identified; 
Specialized suppliers were not identified;

Substitute goods suppliers were not identified;

Income reinvested in activity was identified in two of the three, $66.6 \%$;

Burden sharing and $\mathrm{R} \& \mathrm{D}$ risk was identified in two of the three, $66.6 \%$;

Exchange of experiences on new opportunities has not been identified;

Product lines with higher quality was identified in two of the three, $66.6 \%$;

Pressure in the market has not been identified;

Resource sharing has not been identified;

Strengthening purchasing power has not been identified;

Force to operate in international markets has not been identified;

Specialization production was identified in all three, namely, $100 \%$;

Mass Formation skilled workers was identified in all clusters, $100 \%$.

A summary of the results in percentages of vested benefits identified in clusters is presented in Table 3 .

Table 3. Analysis of the benefits of local production arrangements in \%, according Cezarino and Campomar.

\begin{tabular}{l|l}
\hline Benefits & LPAs \\
\hline Flow of information on the segment & $33,3 \%$. \\
Specialized support infrastructure & $0 \%$ \\
Specialized suppliers & $0 \%$ \\
Substitute goods suppliers & $0 \%$ \\
Investment income in the activity & $66,6 \%$ \\
Burden sharing and R \& D risks & $66,6 \%$ \\
Exchange of experiences on new opportunities & $0 \%$ \\
Product lines with superior quality & $66,6 \%$ \\
Pressure on the market & $0 \%$ \\
Resource Sharing & $0 \%$ \\
Strengthening the purchasing power & $0 \%$ \\
Force to operate in international markets & $0 \%$ \\
Production specialization & $100 \%$ \\
Mass training of skilled workers & $100 \%$ \\
\hline
\end{tabular}

To expand the analysis as to present more benefits identified in the LPAs were made hierarchize option for them, according to their respective percentages of the benefits together, as can be seen in Table 4.

Table 4. Hierarchy of the benefits of local production arrangements in\%, according Cezarino and Campomar.

\begin{tabular}{lll}
\hline $\mathbf{N}^{\mathbf{0}}$ & Benefits & LPAs \\
\hline 1 & Mass training of skilled workers & $100 \%$ \\
2 & Production specialization & $100 \%$ \\
3 & Burden sharing and R \& D risks & $66,6 \%$ \\
4 & Product lines with superior quality & $66,6 \%$ \\
5 & Investment income in the activity & $66,6 \%$ \\
6 & Flow of information on the segment & $33,3 \%$. \\
\hline
\end{tabular}

The results of the Table 4 demonstrate that the burden sharing benefits and R \& D risk, reinvestment of income in the activity, product lines with superior quality, mass training of skilled workers and specialization of production, were the most favorable in the studied clusters.

Especially for mass training of skilled workers and specialization of production, identified in all the surveyed clusters.

To better visualize the benefits identified in the clusters was not made the choice to select them according to their respective percentages as shown in Table 5 .

Table 5. Benefits unidentified in local clusters in\%, according Cezarino and Campomar.

\begin{tabular}{lll}
\hline $\mathbf{N}^{\mathbf{0}}$ & Benefits & LPAs \\
\hline 1 & Pressure on the market & $0 \%$ \\
2 & Resource Sharing & $0 \%$ \\
3 & Strengthening the purchasing power & $0 \%$ \\
4 & Exchange of experiences on new opportunities & $0 \%$ \\
5 & Specialized suppliers & $0 \%$ \\
6 & Specialized support infrastructure & $0 \%$ \\
7 & Force to operate in international markets & $0 \%$ \\
8 & Substitute goods suppliers & $0 \%$ \\
\hline
\end{tabular}

Those of Table 5 results suggest that the pressure of benefits on the market, sharing of resources, strengthen purchasing power, exchange of experiences on new opportunities, specialized suppliers, specialized support infrastructure, power to operate in international markets and substitute goods suppliers were not favorable in the studied clusters as they were not identified in them.

\section{Conclusion}

The research question of this work is to verify that the competitive gains are provided by clusters studied.

So for the research and to broaden the understanding of how are the competitive gains provided by clusters, defined the purpose of this article was to study the competitive gains of selected clusters, located in the state of Goiás. In this study, three were analyzed clusters, located in the state of Goias.

The survey results revealed some relevant points about the competitive gains provided by the studied clusters, among which can be highlighted:

Benefits identified with great emphasis in the studied clusters, we observed: specialization of mass production and training of skilled workers identified in all clusters.

The theoretical approaches that served as basis for the development of this research, along with the empirical findings found brought contributions to both the academic context as to the business environment. One of the contributions of this study refers to the fact that the competitive gains in clusters being considered by several authors as emerging issues. Thus, these issues require further clarification, to increase knowledge concerning this area.

From a pragmatic point of view, this research can bring a useful contribution to people and organizations, we can count on this study to make decisions and undertake new actions.

To continue this research is suggested:

Extension of this research using other sources of evidence;

New studies involving the participation of other clusters. 


\section{References}

[1] CASAROTTO, F. M.; PIRES, L. H. (2001). networks of small and medium enterprises and local development. São Paulo: Atlas.

[2] VENTURI, J. L.; FELIPE, M. O. (2007). Multivariate analysis of the factors that influence the permanence of companies in local clusters. Journal of Unifebe, v. 1, p. 109-123.

[3] CASTRO, L. H. (2009). Local Productive Arrangement. Series Collective Enterprises - SEBRAE. 40p.

[4] ISSA, A. A.; BRENE, P. R. A.; CARAVIERI, A. M. M.; SON, U. A. S A. (2015). Study of LPA's São Bento do Sul (SC) and Arapongas (PR) from multipliers of production, employment and income. Scientific magazine Capital - Electronics (ECMR), v. 13 , no. 1 , p. $95-114$.

[5] BRITO, J.; ALBAGLI, S. (2003). Glossary arrangements and productive and innovative local systems. Research Network on Production Systems and Innovative Local (REDESIST), Rio de Janeiro.

[6] MARINI, M. J.; SILVA, C. L. (2014). Measuring the internal potential for development of a Local Productive Arrangement: a proposal for practical application, Journal of Urban Management, vol. 6, no. 2, p. 236-248.

[7] SACHS, I. (2003). Social inclusion for the work: human development, decent work and the future of small entrepreneurs. Rio de Janeiro: Garamont.

[8] PORTER, M. E. (1998). Cluster and new economics of competition. Harvard Business Review, n. 6, p. 77-90.

[9] CAPORALL, R.; VOLKER, P. (2004). Methodology development of local clusters: Promos Project - Sebrae - IDB: version 2.0. Brasilia: SEBRAE.

[10] IPIRANGA, A. S. R.; AMORIM, M. A.; FARIA. M. V. C. M. (2007). Technology social mobilization for local clusters: a proposal for applicability. Notebooks Ebape.BR, v. 5 n. 3, p. $1-23$.

[11] SANTOS, A. M. M. M.; GUARNERI, L. S. (2000). General characteristics of support and local clusters. Magazine BNDES, n. 12 , p. $195-204$.

[12] PUGA, F. P. (2003). Support to MSMEs Alternatives located in local clusters. [S. L.] BNDES.

[13] IACONO, A.; NAGANO, M. S. (2010). Interaction and Cooperation in clusters of Micro and Small Enterprises. Journal of Small and Medium Enterprises, Campo Limpo Paulista, v. 3, n. 3, p. 4-19.

[14] AZEVEDO, R. R.; SILVEIRA, M. A. P.; CUNHA, C. A.; LOPES, D.; FERNANDES, J. L. N.; PERETI, L. C. (2013). The Importance of Information Exchanges For Business Relationships in a cluster of Design and Architecture. Journal of Small and Medium Enterprises, Campo Limpo Paulista, v. 7, no. 1, p. 17-31.

[15] Marini, M. J.; SILVA, C. L. (2010). Public Policies and Local Productive Arrangements: LPA An Analysis of Parana Southwest Sewing. Magazine Paranaense Development, Curitiba, n.118, p. 87-112.

[16] SILVA, M. E.; SANTOS, J. G.; CANDID, G, A. (2011). systemic competitiveness in the local productive arrangement of mattresses in large-PB meadow. Journal of Small and Medium Enterprises, Campo Limpo Paulista, v. 5, no. 2, p. 91-105.

[17] RIBEIRO, K. A.; BIRTH, D. C.; JUNIOR, N. F. C.; MORATO, J. A. Q. (2013). Local Productive Arrangement (LPA) As Strategy To facilitate the marketing of the Beekeeper Borders Irrigation Perimeter Senator Nilo Coelho in Petrolina-Pe. Journal of Management, Finance and Accounting, UNEB, Salvador, v. 3, n. 2, p. 99-120.

[18] TEIXEIRA, M. C.; TEIXEIRA, R. M. (2010). Relations, Cooperation and Governance in Local Productive Arrangements: The Case of LPA Wood and Furniture of the state of Rondonia. He reads. Rev. electr. adm, v. 17, no. 1, p. 237-269.

[19] VIDIGAL, V. G.; CAMPOS, A. C. (2011), Evolution of Local Productive Arrangements (LPA) Shoes in Brazil: An Analysis From the data of the Rais. Analysis, Porto Alegre, v. 22, no. 1, p. 56-71.

[20] SARACENI, A. V.; JR, P. P. A.; RESENDE, L. M. (2013). Knowledge Management in Clusters of Enterprises: Value Network as instrument to strengthen the Knowledge Exchange. R. electr. Strategy \& business, Florianopolis, v. 6, no. 1, p. 89-107.

[21] SORDI, J. O.; MEIRELES, M. (2011). Local Productive Arrangement or agglomerate companies? Distinction by Attributes Associated Thematic Transfer Information. Rap, Rio de Janeiro, v. 46, no. 3, p. 75-94.

[22] VIEIRA, A. M.; GALDAMEZ, E. V. C.; SOUZA, F. B.; OLIVEIRA, O. J. (2013). Guidelines for Collective Development Continuous Improvement in Local Productive Arrangements. Management \& Production, San Carlos, v. 20, no. 2, p. 469-480.

[23] MASQUIETTO, C. D.; NETO, M. S.; GIULIANI, C. (2010). Identification of Local Productive Arrangements: The Case of Productive Arrangement Alcohol Piracicaba Site. Magazine Management \& Regionality, v. 26, no. 77, p. 75-87.

[24] CASTRO, S. D.; ESTEVAM, L. A. (2010). Critical analysis mapping and policy for Local Productive Arrangements in the State of Goiás. In: Renato Ramos Campos; Fabio Stallivieri; Marco Antonio Vargas; Marcelo Matos. (Org.). State Policies for Local Production Arrangements in the South, Southeast and Midwest of Brazil. 1ed. Rio de Janeiro: E-Papers, p. 335-370.

[25] CALHEIROS, D. O. (2010). Local Productive Arrangement: Opportunities and Challenges to the Implementation of the Productive Chain of Viticulture at the Jundiaí region. Journal of Small and Medium Enterprises, Campo Limpo Paulista, v. 4, n. 1, p. 127-142.

[26] SILVEIRA, M. A. P.; PEREIRA, J. A.; DUGO, J. C.; RUIZ, P. S. L. (2011). The Plastics Industries of São Caetano do Sul and Its Potential for Performance in Cluster Form. Journal of Small and Medium Enterprises, Campo Limpo Paulista, v. 5, no. 2, p. 21-37.

[27] MARTINS, R. (2013). Collaboration in Small Companies in Logistics Processes and Medium in clusters. Journal of Small and Medium Enterprises, Campo Limpo Paulista, v. 7, no. 2, p. 49-65. 
[28] NADAE, J.; GALDAMEZ, E. V. C.; CARPINETTI, L. C.; SOUZA, F. B.; OLIVEIRA. O. J. (2014). method to develop integrated management practices in industrial clusters. Production Magazine, vol. 24, no. 4, p. 776-786.

[29] GONÇALO, C. R.; JUNIOR, E. R. (2012). Social Networks, A Relational Strategies for Diagnostic Tool for the Knowledge Creation in Local Productive Arrangements (LPA). Journal of Small and Medium Enterprises, Campo Limpo Paulista, v. 6, no. 1, p. 20-37.

[30] MACEDO, M. M. (2011). Management of Regional Development and Strategies to Support Policies to Local Clusters: Clusters Traditional and Next Generation or production of territorial systems. Magazine Paranaense Development, Curitiba, n.120, p. 101-112.

[31] REIS, A. P.; NETO, J A. (2012). Learning by cooperation network: knowledge practices in local clusters of software. Production, v. 22, no. 3, p. 345-355.

[32] OliVARES, G. L.; DALCOL, P. R. T. (2014). Contribution Assessment production clusters for local development in the state of Rio de Janeiro. Production Magazine, vol. 24, no. 4, p. 833-846.

[33] SCHMITZ, H.; NADVI, K. (1999). Clustering and Industrialization; introduction. World Development, vol. 27, no. 9, p. 1503-1514.

[34] MARSHALL A. (1982). Principles of Economics. Sao Paulo: Cultural April.

[35] KELLER, P. F. (2008). Clusters, industrial and inter-firm cooperation districts: a literature review. Magazine Economia \& Management, Minas Gerais, v. 8, no. 16, p. 30-47.

[36] MARKUSEN, A. (1995). Investment attraction areas in a changing economic space: a typology of industrial districts. New Economy, vol. 5, no. 2, p. 9-43.

[37] WEGNER D.; MISOCSKY, M. C. (2010). Evaluation of small business network performance: contributions of the approach of the production of meaning. Magazine O \& S, vol. 17, no. 53, p. 345-361.

[38] REZENDE, O.; SERPA, C. A. (2009). Analysis of performance of an exporting cosmetics group under the business perspective: a case study of Beauty Mines Group. Internext - Electronic Journal of International Business at ESPM, v. 4, n. 1, Art. 5, p. 79-99.

[39] SILVA, C. E. L.; HEWINGS, G. J. D. (2010). The decision on investment in human capital in a local productive arrangement (LPA): a theoretical approach. Journal of Economics, vol. 64, no. 1, p. 67-79.

[40] MARION SON, P. J.; SONAGLIO, C. M. (2010). Technological innovations in the mobile industry: an evaluation from the productive concentration of Bento Gonçalves (RS). Journal of Innovation, vol. 9, no. 1, p. 93-118.

[41] GOHR, C. F.; MEDEIROS, R. A.; SANTOS, L. C. (2014). Competitive advantage in a mobile LPA. Pretext, Belo Horizonte, v. 15, no. 4, p. 64-82.

[42] MAZZARO, L. L.; OLIVA, F. L.; GRISI, C. C. H.; DROUVOT, H.; CRISPIM, S.; GASPAR, M. A. (2009). Competitiveness Clusters in the Southeast Asian rubber industry. Journal of Management Sciences, Vol. 11, no. 23, p. 65-86.
[43] CAMPOS, A. C.; PAULA, N. M. (2008). The Industrial Cluster to LPA: a clothing industry analysis Cianorte (PR). Journal of Innovation, vol. 7, no. 1, p.147-176.

[44] GIULIANI, E. (2013). Network dynamics in regional clusters: Evidence from Chile. Research Policy, vol. 42, p. 1406-1419.

[45] WHEAT, A.; WINS, X. (2012). Scope and patterns of innovation cooperation in Spanish service enterprises. Research Policy, vol. 41, no. 3, p. 602-613.

[46] SOUZA, S. D. C.; ARICA, J. A. (2006). Comparative analysis of innovation systems and the Porter diamond in the local clusters approach. Production, v. 16, no. 1, p. 080-087.

[47] CHOI, J.; SANG-HYUN, A.; CHA, M. (2013). The effects of network characteristics on performance of innovation clusters. Expert Systems with Applications, Vol. 40, p. 4511-4518.

[48] SAMPAIO, R. F. (2009). Local productive systems as a strategy for the sustainable development of Abraham Village. PUPPIM DE OLIVEIRA, J. A. (ed.). Small business, local clusters and sustainability. Rio de Janeiro: FGV, Chapter 1, p. 10-39.

[49] BRANDÃO, S. V. (2013). Agricultural productive arrangement in Naturaliste - holy victory antão / p: potential analysis and risk factors for sustainability of local development. In: Proceedings of Pernambuco Academy of Agricultural Science. Recife, v. 10, p. 160-194.

[50] SOUSA, A. R.; BRITO, M. J.; SILVA, P. J.; ARAÚJO, U. P. (2015). Cooperation in LPA Rita do Sapucai saint. Ram, rev. Adm. Mackenzie, São Paulo, v. 16, no. 1, p. 157-187.

[51] CASTRO, S. D. (Coord.) Et. al. (2010). Mapping and Analysis of Policies for Local Production Arrangements in the South, Southeast and Midwest of Brazil. Final report. Summary of Results, Conclusions and Recommendations - Goias Rio de Janeiro.

[52] CEZARINO, L.; CAMPOMAR, M. C. (2006). Competitive Advantage for micro, small and medium businesses: clusters and clusters. E \& G. Economics and Management, vol. 06, p. 143-158.

[53] PORTER, M. (1989). Competitive Advantage: Creating and Sustaining Superior Performance. Rio de Janeiro: Campus.

[54] SCITOVSKY, T. (1954). "Two concepts of external economies", Journal of Political Economy, vol. 62, p. 143-151.

[55] AMATO NETO, J. (2000). Networks of cooperation and regional clusters: opportunities for small and medium enterprises. São Paulo: Atlas.

[56] TRISTAN, H. M. (2000). Cluster and the supply chain from Franca. France: Facef.

[57] HUMPHREY, J.; SCHMITZ, H. (1998). Trust and inter-firm relations in Developing and transition economies. United Kingdom: IDS University of Sussex, v. 34, p. 32-61.

[58] RICHARDSON, R. J. (2008). Social Research: Methods and techniques. São Paulo: Atlas, 3rd ed.

[59] GODOY, A. S. (1995). Introduction to qualitative research and its possibilities. Journal of Business Administration, São Paulo, v. 35 , no. 2 , p. $57-63$.

[60] MALHOTRA, N. K. (2006). Marketing Research: An Applied Orientation. Porto Alegre: Bookman. 
[61] GIL, A. C. (2002). How to develop research projects. 4. ed. São Paulo: Atlas.

[62] MATTAR, F. N. (1996). Marketing Research: Methodology and Planning. São Paulo: Atlas.

[63] YIN, R. K. (2005). Case Study: Planning and methods. Porto Alegre: Bookman.

[64] MIGUEL, P. A. C. (organizer). (2012). Research methodology in engineering production and operations management. Rio de Janeiro: Elsevier 2ed.
[65] EISENHARDT, K. M. (1989). Product Development: Past Research: Present Findings and Future Directions. Academy of Management Journal, vol. 32, no. 3, p. 543-579.

[66] MARCONI, M. A.; LAKATOS, M. E. (2011). Scientific Methodology. 6th ed. São Paulo: Atlas.

[67] TRIVIÑOS, A. N. S. (1987). Introduction to Research in Social Sciences: Qualitative research in education. São Paulo: Atlas. 